June 1-6: VIII European Rheumatology Congress, Helsinki.

October 3-4: Joint Meeting with Spanish Society of Rheumatology, Madrid.

November 28-29: The Heberden Oration. Annual General Meeting and Dinner, Royal College of Physicians, London.

\section{Submission of Abstracts}

All abstracts will be considered anonymously, that is without knowledge of the name(s) of the author(s) or the institution of origin, by the Executive Committee.

Members wishing to present original communications to the Society are therefore asked to prepare abstracts which provide sufficient information for assessing the paper on merit-an assessment which amounts to competitive selection between the various abstracts submitted.

In the preparation and submission of abstracts, the following points should be observed:

(1) Abstracts should not exceed 300 words. Each must be headed by a title, authors' names, institution and address.

(2) An actual summary of the communication is required. This will usually involve:

(i) A brief introduction to the work.

(ii) An outline of the methods used.

(iii) A summary of the results.

(iv) A statement of the main conclusions.

(3) Full references to previous work quoted must be given.

(4) Simple tables may be included. This is an excellent method of summarizing data.

(5) Accepted abstracts will be published as such with the proceedings of the Society in the Annals of the Rheumatic Diseases, so must be received in a form suitable for publication. In particular, statements such as "The data will be discussed" are entirely unacceptable. Abstracts may be revised for publication after the meeting.

(6) Abstracts should be sent to the Senior Honorary Secretary, The Heberden Society, c/o Arthritis and Rheumatism Council, Faraday House, 8-10 Charing Cross Road, London WC2. Abstracts received at least two weeks before each Executive Meeting (normally held on the same day as scientific meetings of the Society) will be assessed at that meeting.

(7) When submitting abstracts, authors must state whether the communication has been or is about to be read at another meeting; or has been or is about to be published.

(8) The normal length of time for presentation of papers is 10 minutes. However, if authors would prefer a longer ( 15 minutes) or shorter ( 5 minutes) time, this should be stated when submitting abstracts. The final allocation of time will however rest with the Executive Committee.

(9) Authors will be notified (i) when an abstract is received, (ii) when it is either accepted or rejected, (iii) when it is placed on a programme for a particular meeting.

(10) It is the author's responsibility to keep the Senior Hon. Secretary informed of the date of publication of any paper submitted to the Society.

\section{Clinical meeting}

The following papers were presented at the Annual General Meeting on November 1 and 2, 1974.

Interpreting the Biological Significance of Rheumatoid Factor. E. M. Badley, J. Ball, and P. H. N. Wood (A.R.C. Epidemiology Research Unit and Rheumatism Research Laboratories, University of Manchester)

Serological results are usually expressed as positive or negative. The simplicity of the resulting analysis is normally regarded as far outweighing the loss of information inevitably involved in dichotomizing the data. It is usually assumed that comparison of different results will be valid, whatever cut-off level is used. This can be justified statistically only if the cumulative titre distributions run in parallel. A hitherto unnoted exception to this generality can arise if the distributions intersect. This is the case when the rheumatoid factor (RF) titre distribution in the Rhondda is compared with those of Leigh and Wensleydale. Depending on the cut-off level chosen, Rhondda can have the most, the least, or an intermediate proportion of seropositive results.

Against this background the biological significance of RF can be assessed. Biologically the simplest test would be a link between RF positivity and death. The only fatal condition associated with seropositivity in the Rhondda was lung cancer; this observation has now been examined in Wensleydale as well, where no association was found. Thus the finding in the Rhondda could well be a chance finding, though we will need the results of a mortality follow-up in Leigh to confirm this.

Associations with various diseases and characteristics not leading to death are more difficult to interpret. Titres show some tendency to increase with age, but the pattern was not sufficiently consistent to warrant correction for age. Sex and occupation were without discernible effect. Comparison of the tests obtained 10 years apart on balance showed a reduction in titre, though tests unreactive on both occasions accounted for the majority of the results. Most persons in the community with a 'positive' test did not in fact have RA, nor were they likely to develop the disease. SCAT titres did not appear to be linked with smoking histories, bronchitis, respiratory tuberculosis (TB), blood pressure levels, or other risk factors for IHD such as cholesterol, although some relation with ECG abnormalities was found.

Rheumatoid Arthritis in the South African Negro. L. Solomon, P. Beighton, H. A. Valkenburg, and G. Robin (Epidemiological Research Unit, Department of Orthopaedic Surgery, University of the Witwatersrand, Johannesburg)

Rheumatoid arthritis, once thought to be rare in tropical and subtropical climes, has now been described in several African populations. However, its precise incidence and 
distribution in these peoples is still unknown, although casual observation suggests that there may be significant differences between Africans and Caucasians, and possibly even between different populations within the African group.

In the present study two epidemiological surveys were carried out, one in a rural, semitribal African population and the other in a fully urbanized African community in Johannesburg. The diagnosis of rheumatoid arthritis was based on the Rome criteria using the three parameters of clinical polyarthritis, radiological evidence of erosive arthritis, and positive serological tests for rheumatoid factor.

In the rural African population the prevalence of 'definite' rheumatoid arthritis was $0.12 \%$; and of 'definite' and 'probable' rheumatoid arthritis combined, $0.87 \%$ of those over 15 years. Such clinical and radiological changes as occurred were invariably mild and no one in the entire survey had features characteristically associated with established rheumatoid arthritis.

In marked contrast, the prevalence of inflammatory polyarthritis in the urban Africans was similar to that in Caucasian populations: 'definite' rheumatoid arthritis occurred in $0.9 \%$ and 'definite' and 'probable' rheumatoid arthritis combined in $3.3 \%$ of those over 15 years. The difference between the two African populations was statistically highly significant $(P=0 \cdot 01)$. Moreover, the form and severity of the clinical and radiological features in the urban community closely resembled those seen in Caucasians; 24 respondents $(4 \cdot 4 \%)$ had clinical polyarthritis, 2 with the classical changes of long-standing rheumatoid arthritis, and $25(4.5 \%)$ had radiological signs of erosive arthritis. In both African groups a positive latex fixation test was recorded in over $10 \%$ of the population tested. No obvious cause for this was found.

The marked intraracial differences in disease pattern shown point to the importance of sociological and environmental factors in the pathogenesis of rheumatoid arthritis.

Rheumatoid Synovitis and Joint Disease. The Relationship Between Arthroscopic and Histological Changes. D. B. Yates and J. T. Scott (Charing Cross Hospital, London W6). Published in full in the Annals, 1975, 34, 1.

Raised Plasma Kininogen Levels in Rheumatoid Arthritis. Response to Indomethacin and Relationship to Clinical Indices. J. N. Sharma, I. J. Zeitlin, P. M. Brooks, and W. C. Dick (Department of Physiology and Pharmacology, University of Strathclyde, Glasgow; and Centre for Rheumatic Diseases and University Department of Medicine, Royal Infirmary, Glasgow)

All previous work suggests that plasma kininogen concentrations in patients with inflammatory seropositive rheumatoid arthritis fall within the normal range (Jasani, Katori, and Lewis, 1969). These results were obtained from patients who were receiving anti-inflammatory drugs.

Plasma kininogen levels were measured by the method of Brocklehurst and Zeitlen (1967) in 7 patients with classical rheumatoid arthritis after withdrawal of all therapy for 48 hours, and again after one week of indomethacin therapy. The levels for plasma kininogen ob- tained after withdrawal of therapy were markedly raised and fell after a week of indomethacin therapy but were still above the levels observed in normal subjects $(n=7)$ and in patients convalescing in an orthopaedic ward with fractures (Table I). The reduction in plasma kininogen values was mirrored by a rise in indomethacin levels and a fall in the articular index of joint tenderness, pain index, and grip strength in these same patients (Table II).

\section{Table I}

\begin{tabular}{ll}
\hline & $\begin{array}{l}\text { Plasma kininogen level (Brady- } \\
\text { kinin equivalents } / \text { ml }) \\
(\text { mean } \pm S D)\end{array}$ \\
\cline { 2 - 2 } $\begin{array}{l}\text { Rheumatoid arthritis }(\mathrm{n}=7) \\
\quad \begin{array}{l}\text { Pre-indomethacin } \\
\text { Post-indomethacin }\end{array}\end{array}$ & $\begin{array}{r}12 \cdot 9 \pm 1 \cdot 2 \\
\text { Fracture patients }(\mathrm{n}=5)\end{array}$ \\
$\begin{array}{l}\text { Normals }(\mathrm{n}=3) \\
\quad \text { Pre-indomethacin }\end{array}$ & $4 \cdot 9 \pm 1 \cdot 2$ \\
Post-indomethacin & $5 \cdot 0 \pm 1 \cdot 2$ \\
\hline
\end{tabular}

Table II

\begin{tabular}{|c|c|c|}
\hline & Pre-indomethacin & Post-indomethacin \\
\hline $\begin{array}{l}\text { Articular index } \\
\quad(\text { mean }\end{array}$ & $16 \cdot 6 \pm 9 \cdot 3$ & $11 \cdot 9=4 \cdot 2$ \\
\hline $\begin{array}{l}\text { Pain index } \\
\quad(\text { mean } \\
\text { SEM })\end{array}$ & $3 \cdot 3 \pm 0 \cdot 7$ & $1.9 \div 0.4$ \\
\hline
\end{tabular}

Time course studies in a further 3 patients with rheums toid arthritis in whom all drugs were withheld for 48 houns and indomethacin $(150 \mathrm{mg} / \mathrm{d})$ was administered for 7 days confirm these findings and show that the fall in plasma kininogen occurs within 4 hours of drug administration. Indomethacin will not produce a fall in kininogen values in normal subjects nor in fracture patients and does not directly affect the bioassay. We have shown that the plasma kininogen concentration in patients with untreated rheumatoid arthritis is raised and falls with the use of indomethacin. The interaction and inter-relationships between anti-inflammatory drugs and prostaglandin and kinin, chemical mediators of inflammation, requires reconsideration. Whereas it is recognized that indomethacin will inhibit the prostaglandin synthetase enzymes, this is the first report which documents an effect upon the kinin system.

\section{References}

Brocklehurst, W. E., AND Zeiti in, I. J. (1967) J. Physiol., 191, 417 (Determination of plasma kinin and kininogen levels in man)

JASANI, M. K., KATORI, M., AND Lewis, G. P. (1969) Ann. rheum. Dis., 28, 497 (Intracellular enzymes and kinin enzymes in synovial fluid $\mathrm{N}$ in joint diseases. Origin and relation to disease category)

LeE, P., WebB, J., ANDERSON, J., AND BuChANAN, W. W. (1973) Brit. N med.J., 2, 685 (Method for assessing therapeutic potential of antiinflammatory anti-rheumatic drugs in rheumatoid arthritis)

Ritchie, D. M., Boyle, J. A., MCINNES, J. M., JASANI, M.K., DAlakos, $\omega$ T. G. Grieveson, P. AND BuChanaN, W. W. (1968) Q.J. Med., 37,393 (Clinical studies with an articular index for assessment of joint tenderness in patients with rheumatoid arthritis)

Aortic Valve Incompetence and Replacement in Rheuma- $\stackrel{\mathscr{C}}{?}$ toid Arthritis. J. M. I. Iveson, U. Thadani, M. Ionescu, and V. Wright (Department of Rheumatology, Cardiology and $\bar{O}$ Cardiothoracic Surgery, General Infirmary at Leeds). Published in full in the Annals, 1975, 34, 312. 